\title{
Feohifomicosis de tipo tumoral por Cladophialophora spp.
}

\author{
Manuel Martínez-Gómez'; Miguel Mateo Cuervo-López²; Juan David Ruíz-Restrepo³; \\ María del Pilar Jiménez-Alzate ${ }^{4}$
}

\section{RESUMEN}

Introducción: la feohifomicosis es una infección micótica que ocurre especialmente en pacientes inmunosuprimidos y que provoca lesiones cutáneas y, ocasionalmente, en otros órganos. La histopatología, el cultivo y la biología molecular son parte del estudio diagnóstico. El tratamiento incluye la combinación de terapia antimicótica sistémica e intervenciones quirúrgicas.

Presentación del caso: hombre de 61 años, diabético y trasplantado renal, con historia de 1 año de lesión ulcerada en rodilla derecha, no dolorosa y secretante. Histopatológicamente se observaron hifas dematiáceas, con diagnóstico presuntivo de feohifomicosis. Ante la mala evolución clínica a pesar del uso de itraconazol, requirió inicio de anfotericina B y manejo quirúrgico, de donde se aisló en cultivo Cladophialophora spp., confirmando así el diagnóstico. Actualmente está recibiendo voriconazol, con mejoría satisfactoria.

Conclusiones: se presenta un caso de feohifomicosis tumoral en un paciente inmunosuprimido, con poca mejoría al uso de terapia sistémica, que requirió combinación con manejo quirúrgico para obtener mejores resultados.

PALABRAS CLAVE: feohifomicosis; inmunosupresión; carcinoma de células escamosas; trasplante.

1. Médico, residente de dermatología, Sección de dermatología, Facultad de Medicina, Universidad de Antioquia y Hospital Universitario San Vicente Fundación. ORCID https://orcid.org/oooo-ooo1-6593-4275

2. Médico, residente de dermatología, Sección de dermatología, Facultad de Medicina, Universidad de Antioquia y Hospital Universitario San Vicente Fundación. ORCID https://orcid.org/oooo-0002-6301-6590

3. Patólogo, docente de Dermatopatología, Sección de Dermatología, Centro de Investigaciones Dermatológicas CIDERM, Facultad de Medicina, Universidad de Antioquia. ORCID https://orcid.org/oooo-0oo2-2370-2916

4. Médica, doctora en Micología Médica, Departamento de microbiología y parasitología, Facultad de Medicina, Universidad de Antioquia. ORCID https://orcid.org/oooo-0002-7493-4258

Correspondencia: Manuel Martínez Gómez; email: manuo607@hotmail.com

Recibido: $17 / 04 / 20$; aceptado: 04/05/20

Cómo citar: Martínez-Gómez MA, Cuervo-López MM, Ruíz-Restrepo JD, Jiménez-Alzate MP. Feohifomicosis de tipo tumoral por Cladophialophora spp. Rev Asoc Colomb Dermatol. 2020;28(2): 164-168. DOI:

Financiación: ninguna, conflictos de interés: ninguno 


\section{TUMOR-LIKE PHAEOHYPHOMYCOSIS DUE TO CLADOPHIALOPHORA SPP}

\section{SUMMARY}

Introduction: The phaeohyphomycosis are mycotic infections, occurring specially in immunocompromised patients, producing many clinical manifestations. Histopathology, cultures, and molecular biology studies are among the diagnosis approach. The treatment includes the combination of systemic antimycotic therapy with surgical interventions.

Case presentation: male patient, 61 years old, diabetic and with kidney transplant; has a history of an ulcered wound over his right knee, unpainful and with secretion, since the last year. On skin biopsy there were observed dematiaceous hyphae, making the presumptive diagnosis of phaeohyphomycosis. After poor clinical evolution using itraconazole and developing systemic symptoms and deep collections, he required the use of amphotericin B and surgical management, obtaining Cladophialophora spp in the culture, confirming the diagnosis. At the time he is receiving voriconazole with satisfying recovery.

Conclusions: we present the case of a tumor-like phaeohyphomycosis in an immunocompromised patient, with poor improvement using systemic therapy only, requiring combination with surgical management.

KEYWORDS: Phaeohyphomycosis; Immunosuppression; Squamous cell carcinoma; Transplant.

\section{INTRODUCCIÓN}

Las feohifomicosis son un grupo de infecciones por hongos pigmentados que afectan principalmente a personas inmunosuprimidas. Los principales géneros involucrados son Alternaria, Bipolaris, Cladophialophora, Rhinocladiella y Exophiala. Se encuentran principalmente en suelo de material en descomposición, y la infección se adquiere por traumatismos o por inhalación. El espectro de manifestaciones clínicas va desde compromiso localizado en piel hasta diseminación a diferentes órganos, principalmente al sistema nervioso central (SNC). El diagnóstico se hace tomando muestras del tejido afectado para estudios microbiológicos directos, cultivos, histopatología y, recientemente, el uso de biología molecular. Su tratamiento es generalmente complejo y este depende de la extensión de la enfermedad; se ha observado que el uso de antimicóticos en combinación con intervenciones quirúrgicas ha demostrado mayor tasa de curación.

A continuación, se realiza la descripción del caso de un paciente con múltiples comorbilidades, quien pre- sentó un cuadro clínico atípico de infección por hongos dematiáceos, que se convirtió en un reto diagnóstico y terapéutico, requiriendo manejo interdisciplinario en un hospital de alta complejidad. Se presentan las fotos clínicas, histopatológicas y de radiología.

\section{PRESENTACIÓN DEL CASO}

Paciente masculino de 61 años, natural del nordeste antioqueño y cesante. Antecedentes de diabetes mellitus insulinorrequiriente y trasplante renal con inmunosupresión crónica con micofenolato, $1 \mathrm{~g} / \mathrm{d}$, tacrolimús, $1 \mathrm{mg} / \mathrm{d}$, y prednisolona, $5 \mathrm{mg} / \mathrm{d}$. Consultó por cuadro de 1 año de evolución de una lesión ulcerada atraumática en la rodilla derecha con aumento progresivo de tamaño, no dolorosa y que ocasionalmente tenía secreción amarilla (figura 1A). Fue hospitalizado en varias ocasiones y tratado para infección de tejidos blandos de origen bacteriano y desbridamientos con mejoría parcial. En la primera evaluación por dermatología se sospechó un carcinoma escamocelular versus una infección granulomatosa (botriomicosis, tuberculosis cutánea o micosis intermedia). 


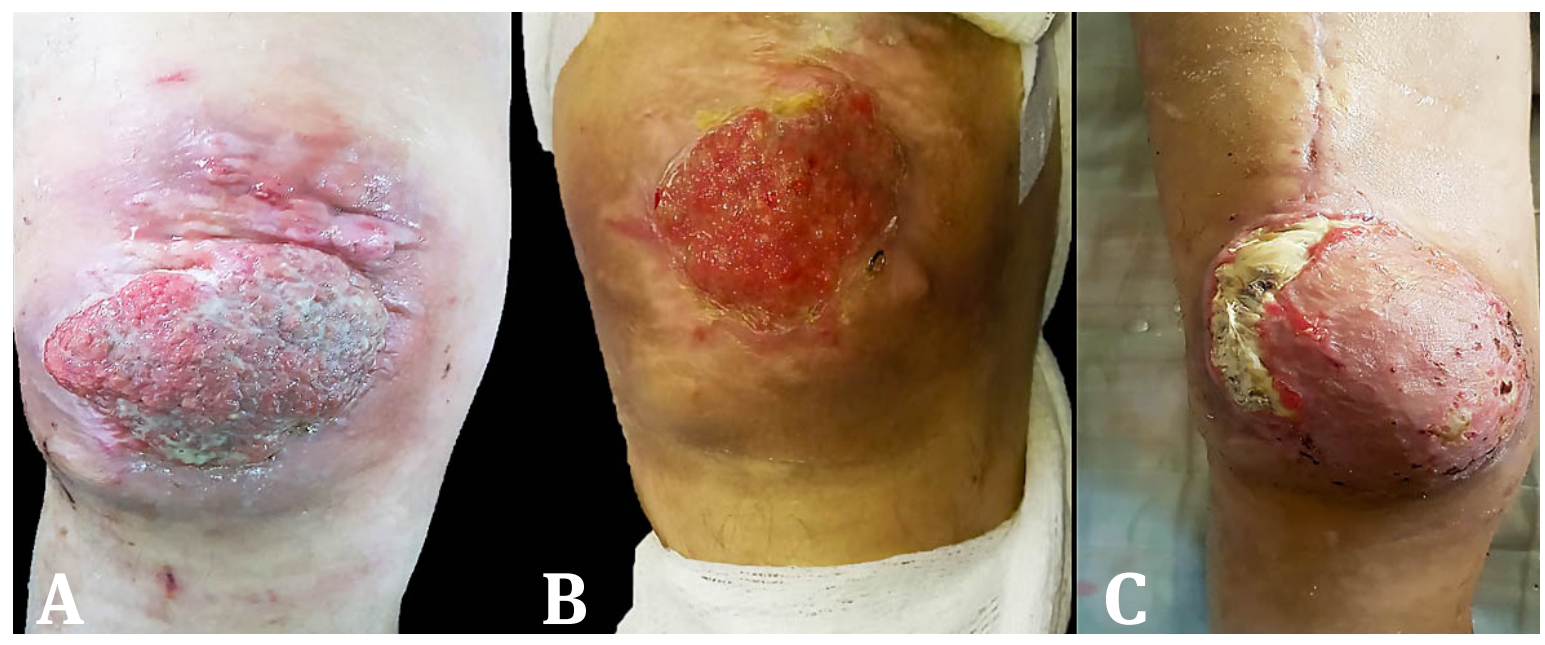

Figura 1. A) Ingreso. Tumor exofítico de superficie rugosa granular de bordes irregulares definidos. B) 1 semana de anfotericina B liposomal. Reducción y aplanamiento del 70\% de la lesión con desaparición de las lesiones satélites. C) 1 mes después de cirugía reconstructiva. Injerto de piel que recubre la rodilla con dehiscencia en extremo lateral. En cara anterior del muslo cicatriz lineal secundaria al desbridamiento.

Al observar hifas dematiáceas septadas en la biopsia de piel se hizo un diagnóstico presuntivo de feohifomicosis, por lo que se inició terapia con itraconazol durante 1 año, con una evolución tórpida. Vuelve a ser hospitalizado por fiebre, síntomas generales y secreción purulenta en rodilla, por lo que se consideró terapia con anfotericina $\mathrm{B}$ liposomal durante 7 días, con mejoría importante (figura 1B); sin embargo, al notar empastamiento sin otros cambios inflamatorios en el muslo izquierdo, se realizó resonancia magnética que demostró colecciones profundas (figura 2), lo que hizo necesaria la resección de la lesión en la rodilla, con lavado y desbridamiento profundo del cuádriceps. Se enviaron las muestras a estudios microbiológicos, de los cuales se aisló en cultivo Cladophialophora spp. y sobreinfección por Corynebacterium striatum, lo que confirmó el diagnóstico inicialmente propuesto de feohifomicosis; en las tinciones se observaron abundantes hifas septadas dematiáceas que dieron cuenta del compromiso profundo por la misma (figura 3). Adicionalmente, presentó disfunción renal multifactorial (asociada al uso de contraste venoso, niveles bajos de inmunosupresores y medicamentos nefrotóxicos). Fue tratado con fosfomicina, polimixina y daptomicina para infección bacteriana y se realizó terapia con presión negativa para ayudar a cerrar el defecto de cobertura en la rodilla. Posteriormente, bajo decisión de junta médica, considerando las comorbilidades y el riesgo de pérdida del tejido de reparación, se optó por corrección con colgajo libre de gastrocnemio y sóleo e injerto de piel de espesor parcial. Se cambió la terapia a voriconazol y actualmente el paciente se encuentra en casa, con una evolución satisfactoria (figura 1C).

\section{DISCUSIÓN}

Los hongos dematiáceos son un grupo heterogéneo de mohos que causan variedad de enfermedades en humanos. La implantación traumática es necesaria para infectar, pero, en ciertos casos, no se es consciente del evento. Hay reportes de casos en individuos aparentemente inmunocompetentes y en pacientes inmunosuprimidos crónicos, como nuestro paciente con trasplante renal, quienes tienen alto riesgo de infecciones localizadas y diseminadas, siendo de estas últimas el SNC el más comprometido. Debido a la mayor frecuencia de tumores malignos en la piel de pacientes inmunosuprimidos, se sospechó inicialmente un carcinoma escamocelular, pero estudios posteriores demostraron el compromiso profundo por una Cladophialophora spp., descartando asimismo otras micosis por hongos dematiáceos, como las cromomicosis, que suelen manifestarse como placas de aspecto verrugoso de crecimiento lento. En nuestra revisión, solo encontramos dos casos con este fenotipo clínico de feohifo- 


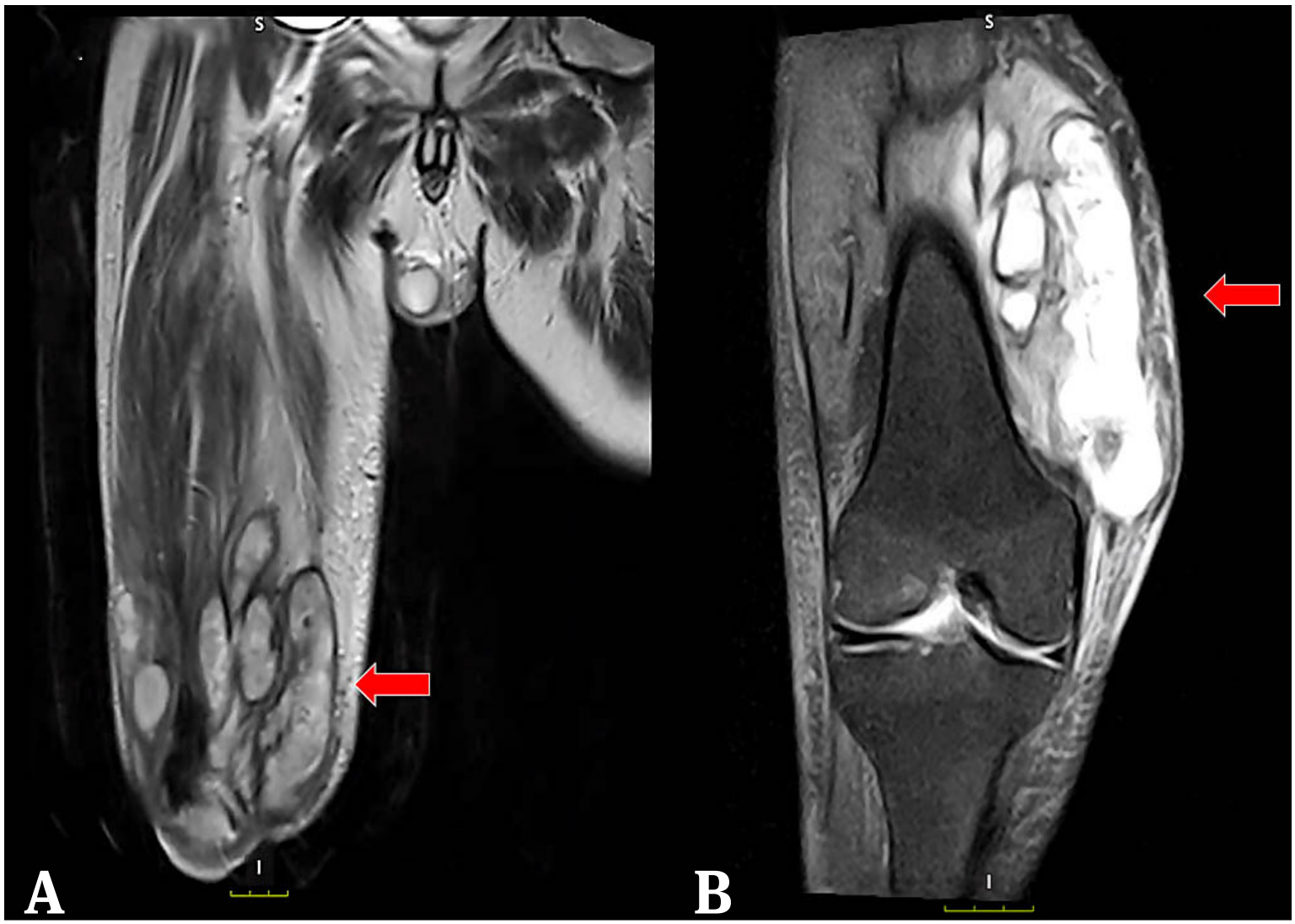

Figura 2. A y B) Resonancia magnética contrastada de muslo $\mathrm{T} 2$ y rodilla T1: Se observan grandes colecciones multi-loculadas comprometiendo compartimentos del cuádriceps y aductores.

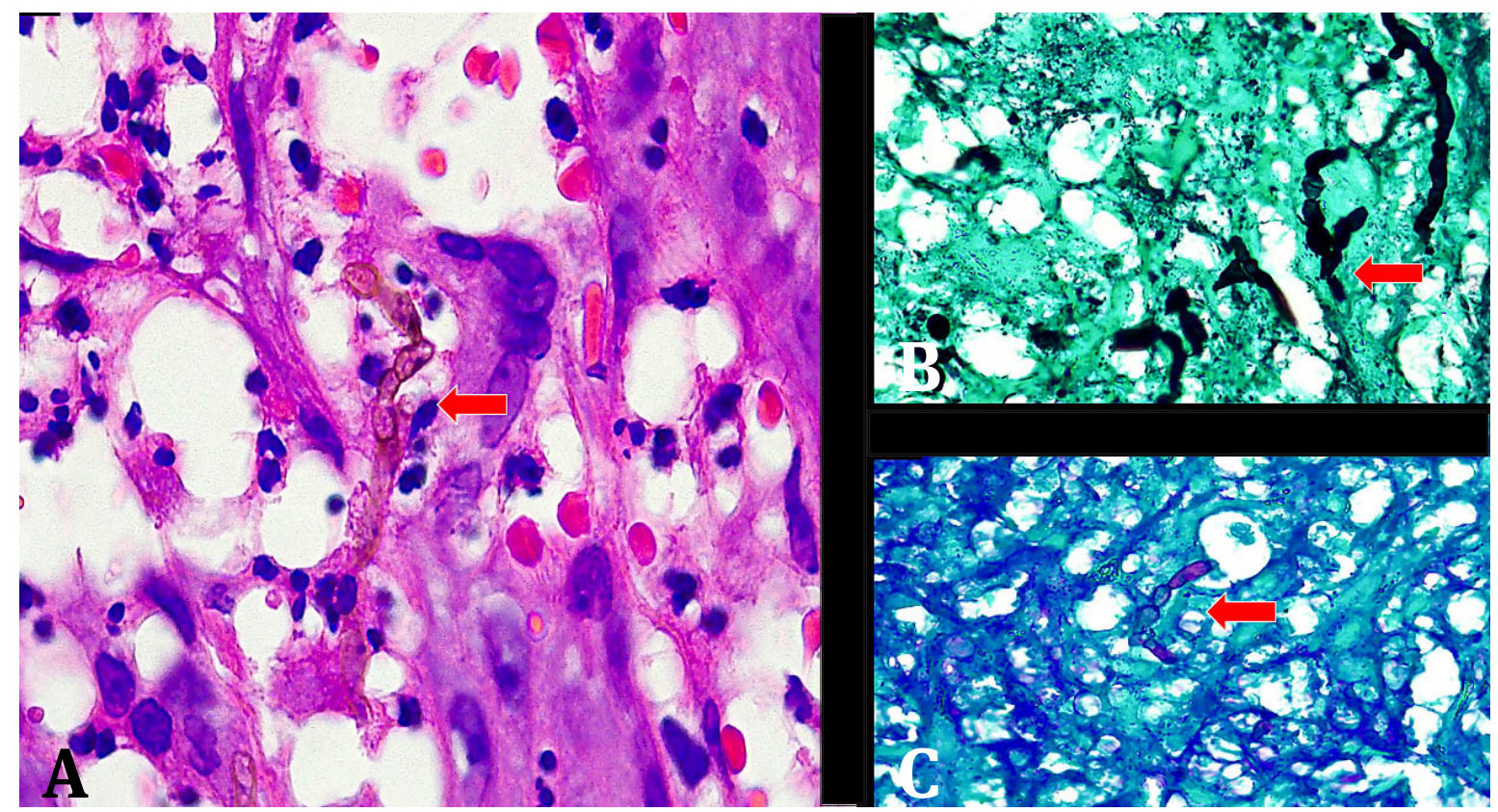

Figura 3. A) Hematoxilina/eosina en 10oX. flecha roja: hifas dematiaceas septadas. B) Plata metenamina en $100 \mathrm{X}$. Flecha roja: positiva para estructuras micóticas compatibles con hifas. C) PAS green en 10oX. Flecha roja: positiva para estructuras micóticas compatibles con hifas 
micosis causados por Alternaria infectoria y Exophiala pisciphila y ninguno por Cladophialophora spp. donde se hayan considerado tumores malignos como diagnóstico diferencial ${ }^{(1,2)}$. Con respecto al tratamiento, se ha demostrado in vitro la sensibilidad de mohos dematiáceos a itraconazol; sin embargo, hay reportes de fallas en algunos pacientes, sobre todo cuando no se hace manejo quirúrgico simultáneo, lo cual podría explicar la falla inicial del paciente al tratamiento con itraconazol. El principal agente fungicida es el mismo sistema inmunitario; por esto, es necesario modular las dosis de inmunosupresores intentando preservar el órgano trasplantado, lo cual fue un reto en este paciente. La cirugía es el método de elección para resecar lesiones localizadas o reducir la carga del hongo de forma tal que el sistema inmunitario y los antimicóticos puedan controlar la infección. Para este paciente fue necesaria la intervención de ortopedia y cirugía plástica, ya que, en ocasiones, los defectos de cobertura amplios necesitan intervenciones especializadas para corregirse ${ }^{(3)}$. Además, se demostró que la terapia con presión negativa, a pesar de las complicaciones micro y macrovasculares del paciente por la diabetes, provocan una mejoría importante del lecho receptor para los injertos y colgajos, garantizando la supervivencia de estos y evitando la exposición de tejidos susceptibles a infecciones adicionales.

\section{CONCLUSIÓN}

Presentamos el caso de un paciente con una feohifomicosis de tipo tumoral que afectó tejidos blandos superficiales y profundos. Inicialmente no respondió a la terapia antimicótica y requirió ajustes de la inmunosupresión, cirugía, desbridamiento, reconstrucción y ajuste de la terapia antimicrobiana, que demandó la atención multidisciplinaria de alta complejidad para lograr mejoría y control de la micosis y sus complicaciones.

\section{REFERENCIAS}

1. Sughayer M, Degirolami PC, Khettry U, Korzeniowski D, Grumney A, Pasarell L, R McGinnis M. Human Infection Caused by Exophiala pisciphila: Case Report and Review. Rev Infect Dis. 1991;13(3):379-82. doi: 10.1093/clinids/13.3.379

2. Tambasco D, D'Ettorre M, Bracaglia R, Massi G, Posteraro B, Torelli R, De Simone C, Capizzi R. A Suspected Squamous Cell Carcinoma in a Renal Transplant Recipient Revealing a Rare Cutaneous Phaeohyphomycosis by Alternaria infectoria. J Cutan Med Surg. 2014; 16(2):131-4. doi: 10.2310/7750.2011.10129

3. Cho Y, Lee J, Chung D. Pedicled chimeric gastrocnemius-medial sural artery adipofascial flap for reconstruction of anterolateral defects of the knee. Microsurgery. 2017;37(3):206-11. doi: $10.1002 /$ micr.22436

\section{Puntos clave}

- Las feohifomicosis son un grupo de infecciones por hongos pigmentados que afectan principalmente a personas inmunosuprimidas.

- El espectro de manifestaciones clínicas va desde un compromiso localizado en piel hasta infecciones diseminadas.

- El diagnóstico se hace por la combinación de estudios microbiológicos, histopatológicos y moleculares.

- Su tratamiento se basa en la combinación de la terapia antimicótica, la cirugía y la disminución de las terapias inmunosupresoras sin impactar en la viabilidad del órgano trasplantado.

- La falla terapéutica es más frecuente en casos de monoterapia y siempre se debe sospechar la sobreinfección bacteriana, que en el caso de inmunosuprimidos puede darse por agentes infecciosos poco frecuentes.

- $\quad$ El trabajo transdisciplinario es la clave del éxito en estos casos. 